\title{
The Release of Elements of Dental Casting Alloys into Cell-culture Medium
}

\author{
J.C. WATAHA, R.G. CRAIG, and C.T. HANKS \\ The University of Michigan School of Dentistry, 1011 N. University Avenue, Ann Arbor, Michigan 48109-1078
}

Ten dental casting alloys were tested for alloy-element release into cell-culture medium, and this release was related to alloy composition, alloy microstructure, and alloy cytotoxicity (previously determined). Cell-culture medium was analyzed for alloy elements by flame atomic absorption. Concentrations of elements in the medium were normalized by dividing them by their atomic abundance in the alloy, giving element mediumalloy ratios (EMA ratios). Results showed that $\mathrm{Au}$, In, and $\mathrm{Pd}$ generally did not dissolve into the medium, but that $\mathrm{Ag}, \mathrm{Cd}$, $\mathrm{Cu}, \mathrm{Ga}, \mathrm{Ni}$, and $\mathrm{Zn}$ frequently dissolved. Comparison of EMA ratios for $\mathrm{Ag}, \mathrm{Cu}$, and $\mathrm{Zn}$ showed that each element retained a behavioral identity in diverse metallurgical environments, but that these environments influenced the release behavior to some degree. Some EMA ratios in multiphase alloys were greater than those in solid solutions, and EMA ratios showed great diversity within all the alloys. Nominal composition seemed to be of little value in the prediction of metal release unless the composition supported multiple-phase formation. In addition, release of alloy elements did not, in itself, completely predict alloy cytotoxicity measured previously. However, cytotoxicity was associated with metal release in each case. The commercial alloys used in this study exhibited more complex and less predictable release behavior than did the simpler ternary alloy systems used by previous investigators. It is believed that the use of commercial preparations is necessary for their in vivo behavior to be modeled.

\section{J Dent Res 70(6):1014-1018, June, 1991}

\section{Introduction.}

The release of metal cations, compounds, or particulates from dental alloys is of interest in both in vivo and in vitro environments. The in vivo release is of interest because of the toxic (local and systemic), immunogenic, mutagenic, and chemotactic effects these components could exert. The in vitro release is of interest because in vitro tests have been developed to help in the understanding and prediction of the complex in vivo release phenomena.

The in vitro release of alloy elements has been studied previously in a variety of dental metals and environments. For example, Bergman and Ginstrup (1975) used externally applied potentials and atomic absorption to study the release of $\mathrm{Cd}, \mathrm{Cu}$, and $\mathrm{Zn}$ from dental gold solders. They reported that elements were released at different rates, and that these rates were dependent upon the applied potential but independent of the $\mathrm{pH}$. Brune (1988) used nuclear corrosion monitoring (NCM) and electron microscopy (ESCA) to measure the release of metals from a variety of alloys, including stainless steels and dental amalgam. He found that release of elements from a surface sometimes changed the surface composition to favor

Received for publication October 19,1990

Accepted for publication January 30, 1991

This investigation was supported by USPHS Grants 5 T32 DE07057, 1 P50 DE09296, and RO1 DE07987 from the National Institute of Dental Research, Bethesda, MD 20892. passivation of that surface, but that subsequent scratching of the surface could re-initiate the corrosive process. Covington et al. (1985) studied the release of $\mathrm{Ni}$ and $\mathrm{Be}$ from base-metal dental-casting alloys in acidified saliva at several $\mathrm{pH}$ levels. They found that decreased $\mathrm{pH}$ and increased time up to 120 days increased the levels of $\mathrm{Ni}$ and $\mathrm{Be}$. Johansson et al. (1989) evaluated corrosion of $\mathrm{Cu}-$, $\mathrm{Ni}$-, and $\mathrm{Au}$-based dental alloys in artificial saliva and saline solutions by microphotography and SEM. They reported that $\mathrm{Cu}$-based alloys showed more tarnish and corrosion than did $\mathrm{Ni}$ or $\mathrm{Au}$ alloys, and that $\mathrm{Be}$ containing $\mathrm{Ni}$ alloys corroded more than did $\mathrm{Ni}$ alloys without Be. Recently, Goehlich and Marek (1990) reported that $\mathrm{Cu}$ release was greater than $\mathrm{Co}$ for $\mathrm{Pd}-\mathrm{Cu}$ and $\mathrm{Pd}-\mathrm{Co}$ alloys because Co release was limited by passive film formation.

The cytotoxicity of over 30 dental casting alloys and pure metals has been reported by Craig and Hanks (1990). A preliminary investigation showed that significant metal release occurred from some of these alloys (Wataha et al., 1989). The purpose of the present study was to (1) determine the amount of alloy elements released from ten of these casting alloys under standard cell-culture conditions, (2) relate this release to the composition and microstructure of the alloys, and (3) relate this release to the toxicity of the alloys as previously reported.

\section{Materials and methods.}

Commercial alloys were used to help ensure clinical relevance. Simpler binary or ternary alloy systems were not used because they lacked components such as grain refiners, which might significantly alter their release behavior.

Ten alloys were used in these experiments (six samples of each alloy). The compositions and microstructures of the alloys are listed in Table 1. Fig. 1 shows the dimensions of the samples used in these tests. The sample thickness was such that $0.5 \mathrm{~mL}$ of cell-culture medium would come into contact with the alloy just below the top of the disc portion of the sample (giving an area of exposure of $65 \mathrm{~mm}^{2}$ ).

Polishing procedures were designed to be similar to those used clinically, and were identical to those employed by Craig and Hanks (1990). Tripoli was applied by a $2.5-\mathrm{cm}$ felt wheel rotating at approximately $3200 \mathrm{rpm}$ (dental bench lathe, high speed), followed by rouge, which was applied by a $2.5-\mathrm{cm} \mathrm{rag}$ wheel. Separate wheels were used for each alloy, and separate rouge and Tripoli were also used. These measures were taken to prevent the possibility of cross-contamination of alloys via the polishing wheels or polishing compounds.

An extra-soft toothbrush was used to scrub the polished samples with a Jelenko Polishing Compound Remover (JPCR) solution consisting of three parts water to one part JPCR. After the samples were rinsed, they were submerged in JCPR solution and ultrasonically treated for five min. Samples were then scrubbed with an Alconox/water solution and rinsed with distilled water. Samples were submerged in distilled water and swirled for two min. The water was replaced with $95 \% \mathrm{v} / \mathrm{v}$ ethanol in water, and swirling was continued for five min. The samples were then transferred to a sterile cell-culture tray and submerged again in ethanol solution for $20 \mathrm{~min}$. Finally, the 
TABLE 1

COMPOSITIONS AND MICROSTRUCTURES OF ALLOYS

\begin{tabular}{|c|c|c|c|c|c|c|c|c|}
\hline Alloy & $\mathrm{Ag}$ & $\mathrm{Au}$ & $\mathrm{Cu}$ & Pd & ompo & Other & $\mathrm{Au}+\mathrm{Pd}+\mathrm{Pt}$ & Microstructure \\
\hline 1 & 11.5 & 49.8 & 31.5 & 2.6 & 3.2 & Pt 1.4 & 53.8 & Single-phase \\
\hline 2 & 30.9 & 32.0 & 27.2 & 8.1 & 1.9 & & 40.1 & Single-phase \\
\hline 3 & 41.7 & 11.8 & & 23.0 & 6.8 & In 16.7 & 34.8 & Single-phase \\
\hline 4 & 62.7 & 1.6 & 10.6 & 22.5 & 0.8 & In 1.8 & 24.1 & Single-phase \\
\hline 5 & 15.2 & 46.6 & 25.6 & & 3.4 & Cd 9.0 & 46.6 & Single-phase \\
\hline 6 & & 51.5 & & 3.8 & & $\begin{array}{c}\mathrm{Ga} \text { 12.6, In } 3.9, \\
\text { Ni } 28.1\end{array}$ & 55.3 & Multi-phase \\
\hline 7 & 24.8 & 42.8 & 25.3 & 3.8 & 3.1 & & 46.6 & Single-phase \\
\hline 8 & 26.7 & 50.1 & & 14.3 & 2.3 & In 5.3, Sn 1.3 & 64.4 & Single-phase \\
\hline 9 & 30.0 & 36.4 & 24.2 & 6.0 & 3.3 & & 42.4 & Single-phase \\
\hline 10 & 54.9 & & 18.3 & 22.8 & 3.0 & B $0.9 \mathrm{Ru} 0.001$ & 22.8 & Multi-phase \\
\hline
\end{tabular}

samples were washed four times with sterile double-distilled water and dried at $60^{\circ} \mathrm{C}$ for approximately ten $\mathrm{h}$.

Cell-culture medium consisted of Dulbecco's Modified Eagle Medium (DMEM) without glutamine, $3 \%$ NuSerum, HEPES $(28 \mathrm{mmol} / \mathrm{L}, \mathrm{pH}=7.2)$, penicillin $(125$ units $/ \mathrm{mL})$, streptomycin $(125 \mu \mathrm{g} / \mathrm{mL})$, gentamycin $(10 \mu \mathrm{g} / \mathrm{mL})$, and glutamine $(2 \mathrm{mmol} / \mathrm{L}$ ). One-half $\mathrm{mL}$ of the medium was added to each well of a 24-well sterile polystyrene cell-culture tray. Immediately after addition of the medium, the alloy samples were added to the wells by means of sterile forceps. Care was taken not to allow the medium to come into contact with the unpolished surfaces of the alloy samples. The culture trays were then incubated at $37^{\circ} \mathrm{C}$ for $72 \mathrm{~h}$ in a $5 \% \mathrm{CO}_{2} / 95 \%$ air atmosphere at $100 \%$ relative humidity.

A Perkin-Elmer 3030B flame atomic absorption spectrophotometer was utilized. Depending upon the element being detected, one of two flames was used: an air-acetylene flame (at $2100^{\circ} \mathrm{C}$ ) or a nitrous oxide-acetylene flame (at $2900^{\circ} \mathrm{C}$ ). An impact bead was used to mix the sample and gases during airacetylene flame use, while a flow spoiler was utilized during nitrous oxide-acetylene flame use. A $10-\mathrm{cm}$ and a $5-\mathrm{cm}$ singleslot burner head were used for the air-acetylene flame and the nitrous oxide-acetylene flame, respectively. The burner heads were aligned in the flame prior to each experiment by means of standard $\mathrm{Cu}^{2+}$ solutions. The nebulizer was also adjusted by $\mathrm{Cu}^{2+}$ solutions if the absorption performance of the solution failed empirically established criteria. In all cases, hollow cathode lamps were used as light sources, and deuterium background was used to minimize matrix interferences. A visual read delay and 0.5 -second read time were used throughout. All samples were aspirated at $0.19 \mathrm{~mL} / \mathrm{s}$. The specific parameters (wavelength, slit width, type flame) used for detection

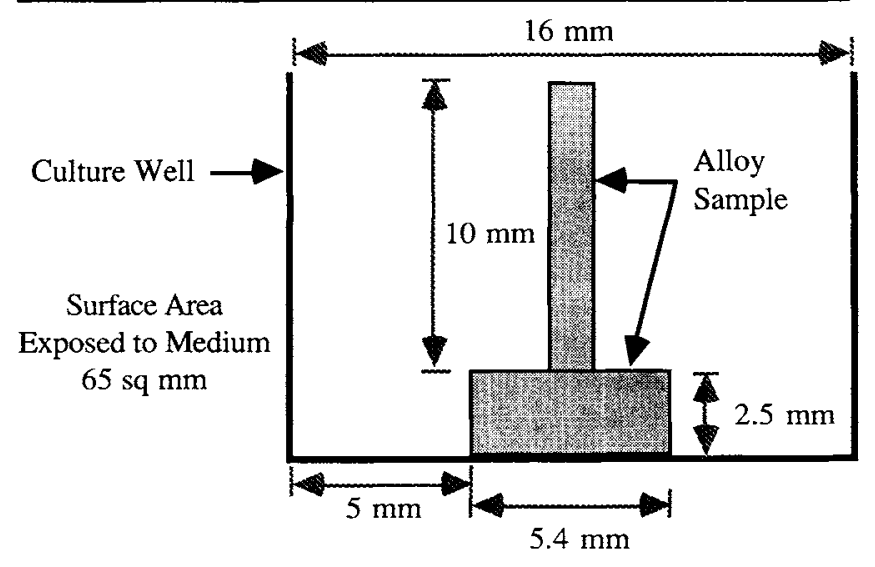

Fig. 1 - Alloy sample and culture-well dimensions. of each element are listed in Table 2. The wavelengths and slit widths were selected after the Perkin-Elmer manual was consulted. Flame and flame conditions were selected empirically to give maximum sensitivity and precision. One or two standard solutions were used for calibration of each element, as per the Perkin-Elmer manual. Standard solutions were prepared by dilution of purchased 1000 -ppm stock solutions (Aldrich, Milwaukee, WI) with double-distilled water. So that the accuracy of the standards could be checked and the precision during each experiment evaluated, separate solutions were prepared that were assayed prior to the cell-culture medium. It was determined that most standards were stable in water at room temperature for at least four months.

The detection limit for each element was defined as the concentration of an element that could be distinguished from background noise with a $95 \%$ confidence interval. In practice, we obtained the detection limits by reading a solution ten or more times, then constructing a 95\% confidence interval by multiplying the standard deviation of these readings by the appropriate $t$ value. This product of the standard deviation and the $t$ value was the detection limit. This number also served as an estimate of the precision for a particular reading.

The native cell-culture medium was evaluated for the presence of the alloy elements as a control in each repetition of the experiment. The only element in this uncontaminated culture medium that was present at concentrations greater than its detection level was $\mathrm{Zn}$. Medium contained between 0.08 and $0.15 \mathrm{ppm}$ of $\mathrm{Zn}$, depending on the batch used. Values shown in the results reflect the adjustment for these background levels.

An element medium-alloy ratio (EMA ratio) was defined as the concentration of an element in cell-culture medium after $72 \mathrm{~h}$ of exposure to an alloy, divided by the atomic percentage abundance of that element in the alloy. These ratios normalized

TABLE 2

ATOMIC ABSORPTION PARAMETERS USED FOR ELEMENTS

\begin{tabular}{cccc}
\hline Element & $\begin{array}{c}\text { Wavelength } \\
(\mathrm{nm})\end{array}$ & $\begin{array}{c}\text { Slit Width } \\
(\mathrm{nm})\end{array}$ & Flame $^{*}$ \\
\hline $\mathrm{Ag}$ & 328.1 & 0.7 & $\mathrm{~A} / \mathrm{A}$ \\
$\mathrm{Au}$ & 242.8 & 0.7 & $\mathrm{~A} / \mathrm{A}$ \\
$\mathrm{Cd}$ & 228.8 & 0.7 & $\mathrm{~A} / \mathrm{A}$ \\
$\mathrm{Cu}$ & 324.8 & 0.7 & $\mathrm{~A} / \mathrm{A}$ \\
$\mathrm{Ga}$ & 287.4 & 0.7 & $\mathrm{~N}_{2} \mathrm{O} / \mathrm{A}$ \\
$\mathrm{In}$ & 303.9 & 0.7 & $\mathrm{~A} / \mathrm{A}$ \\
$\mathrm{Ni}$ & 341.5 & 0.2 & $\mathrm{~A} / \mathrm{A}$ \\
$\mathrm{Pd}$ & 244.8 & 0.2 & $\mathrm{~A} / \mathrm{A}$ \\
$\mathrm{Zn}$ & 213.9 & 0.7 & $\mathrm{~A} / \mathrm{A}$ \\
\hline${ }^{*} \mathrm{~A} / \mathrm{A}=$ air/acetylene. & & \\
$\mathrm{N}_{2} \mathrm{O} / \mathrm{A}=$ nitrous oxide/acetylene. & &
\end{tabular}




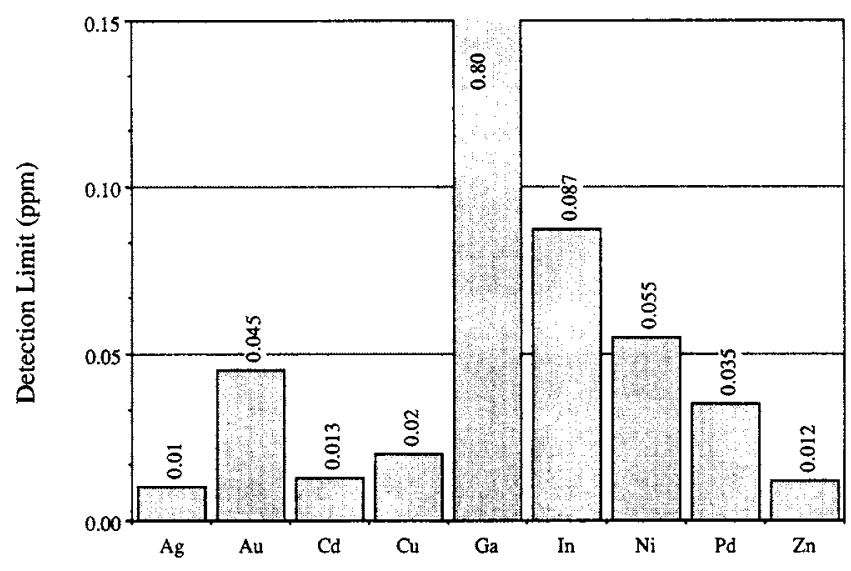

Element

Fig. 2 - Atomic absorption detection limits for elements used in this study. Each value represents the mean from nine experiments $(n=9)$.

the amount of an element that was released to the abundance of the element in the alloy, thereby facilitating comparisons between alloys or between different elements within the same alloy. A larger EMA ratio indicated a greater tendency of an element to be released. EMA ratios were not adjusted for the exposed surface area of the alloy because all samples were the same size. EMA ratios were all determined after $72 \mathrm{~h}$ of incubation.

\section{Results.}

The detection limits obtained in these experiments are shown in Fig. 2. This graph demonstrates the great diversity of sensitivities found among the elements. These detection limits were dependent upon the wavelength and other detection conditions used and were considered to be adequately low and precise for these experiments.

Table 3 lists the concentrations of alloy elements found in the cell-culture medium at $72 \mathrm{~h}$. The values in the Table represent mean concentrations in parts per million (ppm) of five repetitions of the entire experiment; the values for each experiment were the means of the six replicate samples. Values in parentheses represent one standard error of the mean (SEM). In cases where no SEM is listed, it implies that a valid mean and SEM were not calculable because the concentrations were far less than the detection limits, and because noise gave some slightly negative concentrations. In these cases, the concentration was simply listed as zero. The elements $\mathrm{B}, \mathrm{Pt}, \mathrm{Ru}$, and $\mathrm{Sn}$ are not included because either the equipment was not available to assay these elements (B) or the elements had very poor detectability ( $\mathrm{Pt}, \mathrm{Ru}$, and $\mathrm{Sn}) . \mathrm{B}, \mathrm{Pt}, \mathrm{Ru}$, and $\mathrm{Sn}$ were all minor components of the alloys.

In general, the elements $\mathrm{Au}, \mathrm{In}$, and $\mathrm{Pd}$ were not present at detectable levels in solution at $72 \mathrm{~h}$, regardless of their abundance in the alloys. On the other hand, $\mathrm{Ag}, \mathrm{Cd}, \mathrm{Cu}, \mathrm{Ga}, \mathrm{Ni}$, and $\mathrm{Zn}$ were all detectable in the culture medium in at least one alloy. The concentrations of these latter elements in medium varied widely from alloy to alloy. Of significance was the fact that these released concentrations appeared to be reproducible after samples were re-polished and cleaned, as reflected by the SEM values. Coefficients of variation were generally below $10 \%$ unless the mean concentrations approached the detection limits.

Comparisons among the alloys were facilitated by normal- ization of the medium concentration of an element to its atomic percent abundance in the alloy. These EMA ratios are shown in Table 4. Values in the Table were multiplied by a factor of 100 to reduce the number of decimal places. Parentheses indicate ratios that were not statistically different from zero ( $95 \%$ confidence), usually due to the fact that the medium concentrations were near detection levels and/or the abundance of the element in the alloy was very small. In general, standard errors of the means were $10 \%$. When Table 4 is surveyed by element, four magnitudes of ratios are apparent. Au, In, and Pd consistently exhibited ratios at or near zero. Ag generally showed non-zero ratios that ranged between 0 and 1.0. $\mathrm{Cu}, \mathrm{Cd}$, and $\mathrm{Zn}$ exhibited ratios between 1.0 and 10.0 , while $\mathrm{Ga}$ and $\mathrm{Ni}$ had ratios greater than 10.0. Each element seemed to retain a behavioral identity in spite of the diverse metallurgical environments it occupied (hence these general groupings). The release of these elements was not simply proportional to their atomic percent abundance in the alloys, since EMA ratios among alloys for a given element were not equal. However, with $\mathrm{Ag}$, there appeared to be a second-order polynomial relationship between atomic percent abundance and amount of $\mathrm{Ag}$ released into the medium when $\mathrm{Ag}$ was greater than 10 at $\%$ in singlephase alloys (Fig. 3). Similar correlations for $\mathrm{Cu}$ and $\mathrm{Zn}$ were not evident.

When Table 4 is surveyed by alloy, it is apparent that a wide range of EMA ratios could exist in the same alloy. That is, an alloy that exhibited extremely high ratios for one element did not necessarily exhibit high ratios for the others. A good example of this was observed in alloy 6 , where $\mathrm{Ga}$ and $\mathrm{Ni}$ exhibited ratios of 69 and 51, respectively, but $\mathrm{Au}, \mathrm{Pd}$, and In showed ratios at or near zero. While alloy 6 showed the most extreme EMA ratio diversity, some element-to-element diversity occurred in all of the alloys.

Table 4 also shows the effects of composition and microstructure on EMA ratios. Multi-phase alloys had some elements with elevated EMA ratios. Alloy 6 showed extremely high ratios for $\mathrm{Ni}$ and $\mathrm{Ga}$ (discussed above), while alloy 10 exhibited the highest $\mathrm{Ag}$ ratio and the second-highest $\mathrm{Cu}$ ratio. Among single-phase alloys, EMA ratios for a given element varied significantly, demonstrating the effect of composition on release behavior despite a single-phase environment.

\section{Discussion.}

It was encouraging that release of alloy elements was reasonably reproducible after samples were re-polished and cleaned. Table 3 shows that the coefficients of variation for culture medium concentrations of elements were generally less than $10 \%$ when the concentration was at least twice the detection limit. Given the laboratory procedures for polishing and cleaning, and assuming that they created and modified some surface from which release took place, it is interesting that this level of precision in release occurred. Adequate precision made the release phenomenon amenable to study.

The 72-hour EMA ratios listed in Table 4 were found to be most useful for relation of alloy compositions to alloy element release, since they normalized release of elements to composition. It is evident from this Table and from Table 1 that composition had little effect upon the release of $\mathrm{Au}, \mathrm{Pd}$, or In, since these EMA ratios were indistinguishable from zero in all alloys. On the other hand, EMA ratios for $\mathrm{Ag}, \mathrm{Cu}$, and $\mathrm{Zn}$ were clearly influenced by alloy composition, even when alloy microstructures were the same. Although $\mathrm{Cd}, \mathrm{Ni}$, and $\mathrm{Ga}$ also had non-zero EMA ratios, it is not known how composition affected their release, since each occurred in only one alloy system. It appeared that each element had a certain general 
TABLE 3

CONCENTRATIONS (in ppm) OF ALLOY ELEMENTS IN CELL-CULTURE MEDIUM AT $72 \mathrm{H}$

\begin{tabular}{|c|c|c|c|c|c|c|c|c|c|}
\hline Alloy & $\mathrm{Ag}$ & $\mathrm{Au}$ & $\mathrm{Cd}$ & $\mathrm{Cu}$ & $\mathrm{Ga}$ & In & $\mathrm{Ni}$ & $\mathrm{Pd}$ & $\mathrm{Zn}$ \\
\hline 1 & $\begin{array}{c}0.006 \\
(0.002)\end{array}$ & $\begin{array}{c}0.049 \\
(0.016)\end{array}$ & - & $\begin{array}{c}0.533 \\
(0.030)\end{array}$ & - & - & - & $\begin{array}{c}0.014 \\
(0.007)\end{array}$ & $\begin{array}{c}0.022 \\
(0.005)\end{array}$ \\
\hline 2 & $\begin{array}{c}0.044 \\
(0.012)\end{array}$ & $\begin{array}{c}0.018 \\
(0.008)\end{array}$ & - & $\begin{array}{c}0.290 \\
(0.018)\end{array}$ & - & - & - & $\begin{array}{c}0.015 \\
(0.006)\end{array}$ & $\begin{array}{c}0.005 \\
(0.002)\end{array}$ \\
\hline 3 & $\begin{array}{c}0.127 \\
(0.021)\end{array}$ & 0 & - & - & - & $\begin{array}{c}0.112 \\
(0.021)\end{array}$ & - & $\begin{array}{c}0.012 \\
(0.007)\end{array}$ & $\begin{array}{c}0.011 \\
(0.005)\end{array}$ \\
\hline 4 & $\begin{array}{c}0.335 \\
(0.013)\end{array}$ & 0 & - & $\begin{array}{c}0.134 \\
(0.003)\end{array}$ & - & - & - & $\begin{array}{c}0.017 \\
(0.007)\end{array}$ & $\begin{array}{c}0.005 \\
(0.002)\end{array}$ \\
\hline 5 & $\begin{array}{c}0.003 \\
(0.001)\end{array}$ & $\begin{array}{c}0.011 \\
(0.009)\end{array}$ & $\begin{array}{c}0.278 \\
(0.019)\end{array}$ & $\begin{array}{c}0.534 \\
(0.017)\end{array}$ & - & - & - & - & $\begin{array}{c}0.046 \\
(0.006)\end{array}$ \\
\hline 6 & - & 0 & - & - & $\begin{array}{c}8.7 \\
(0.7)\end{array}$ & $\begin{array}{c}0.012 \\
(0.009)\end{array}$ & $\begin{array}{l}14.4 \\
(1.5)\end{array}$ & $\begin{array}{c}0.029 \\
(0.015)\end{array}$ & - \\
\hline 7 & $\begin{array}{c}0.025 \\
(0.005)\end{array}$ & $\begin{array}{c}0.003 \\
(0.003)\end{array}$ & - & $\begin{array}{c}0.302 \\
(0.015)\end{array}$ & - & - & - & 0 & $\begin{array}{c}0.026 \\
(0.006)\end{array}$ \\
\hline 8 & $\begin{array}{c}0.033 \\
(0.003)\end{array}$ & $\begin{array}{c}0.011 \\
(0.007)\end{array}$ & - & - & - & $\begin{array}{c}0.039 \\
(0.024)\end{array}$ & - & $\begin{array}{c}0.007 \\
(0.007)\end{array}$ & $\begin{array}{c}0.176 \\
(0.020)\end{array}$ \\
\hline 9 & $\begin{array}{c}0.130 \\
(0.003)\end{array}$ & $\begin{array}{c}0.013 \\
(0.013)\end{array}$ & - & $\begin{array}{c}1.91 \\
(0.09)\end{array}$ & - & - & - & $\begin{array}{c}0.008 \\
(0.007)\end{array}$ & $\begin{array}{c}0.074 \\
(0.005)\end{array}$ \\
\hline 10 & $\begin{array}{c}0.520 \\
(0.033)\end{array}$ & - & - & $\begin{array}{c}0.543 \\
(0.045)\end{array}$ & - & - & - & $\begin{array}{c}0.014 \\
(0.008)\end{array}$ & $\begin{array}{c}0.016 \\
(0.005)\end{array}$ \\
\hline
\end{tabular}

Values in the form: ppm (SEM), $n=5$; No SEM indicates that SEM were invalid due to values slightly less than zero (caused by levels of the element $<<$ detection limit or slight matrix interferences).

.$--=$ Not checked.

magnitude of lability that was inherent to the element. Noble elements such as Au or Pd were non-labile in any alloy environment. In other metals, the general lability appeared to be element-specific, but specific lability depended upon the alloy composition.

It was clear that simple linear correlations did not occur between the atomic abundance of an element in the alloy and its ultimate concentration in the cell-culture medium; if a simple correlation existed, EMA ratios for a given element among all alloys should have had the same magnitude (Table 4). The second-order polynomial relation between at\% $\mathrm{Ag}$ and $\mathrm{Ag}$ released (Fig. 3) was evidence that such correlations may be complex when present. Alloy microstructure was a factor influencing the lability of the alloy elements. Alloys 6 and 10, the two multi-phase alloys (as determined by EDX analysis), both exhibited elements with large EMA ratios (Table 4 ). This behavior was especially interesting for alloy 6 , since the overall nobility of the alloy (sum of atomic percents of $\mathrm{Au}, \mathrm{Pd}$, and $\mathrm{Pt}$ ) was $55.3 \%$ (Table 1 ), which is traditionally considered to be quite high. It appeared that multi-phase microstructure was more critical to release than was overall nobility.

A comparison of EMA ratios for alloys 2 and 9 was particularly interesting. Ratios for $\mathrm{Ag}, \mathrm{Cu}$, and $\mathrm{Zn}$ in alloy 9 were significantly higher than those of alloy 2 , despite similarities in composition and microstructure (Tables 1 and 4). It is possible that the combination of slightly increased Pd and slightly decreased $\mathrm{Zn}$ in alloy 2 stabilized the release of $\mathrm{Ag}$ and $\mathrm{Cu}$, compared with alloy 9 . These differences demonstrated that a small change in composition may dramatically change element release behavior without altering the microstructure. However, simple correlations between elemental abundance and release were generally inadequate to predict this behavior, and it appeared that complex interactions among all alloy components in a system must be responsible for the release behavior. Overall, it appeared that with the exception of multi-phase microstructure, simple factors (such as at\% Au, overall nobility, or abundance of a particular component) were inadequate to predict release behavior of these alloy systems. It is this apparent lack of predictivity that currently appears to make alloy release characterization mandatory on an individual basis.

A disadvantage of the element medium/alloy ratios (EMA ratios) was that they were not precise when the medium concentration of a cation was low. As the concentration of an element in the medium approached its detection limit, the uncertainty in the concentration became proportionally larger. This problem was amplified when the atomic percent abun-

TABLE 4

ELEMENT MEDIUM/ALLOY RATIOS (EMA ratios) AT $72 \mathrm{H}$

\begin{tabular}{|c|c|c|c|c|c|c|c|c|c|}
\hline Alloy & $\mathrm{Ag}$ & $\mathrm{Au}$ & $\mathrm{Cd}$ & $\mathrm{Cu}$ & $\mathrm{Ga}$ & In & $\mathrm{Ni}$ & $\mathrm{Pd}$ & $\mathrm{Zn}$ \\
\hline 1 & $(0.05)$ & $(0.09)$ & - & 1.70 & - & - & - & $(0.5)$ & 0.7 \\
\hline 2 & 0.14 & $(0.05)$ & - & 1.07 & - & - & - & $(0.2)$ & $(0.3)$ \\
\hline 3 & 0.31 & (0) & - & - & - & 0.7 & - & $(0.05)$ & $(0.2)$ \\
\hline 4 & 0.56 & (0) & - & 1.26 & - & - & - & $(0.08)$ & $(0.6)$ \\
\hline 5 & $(0.02)$ & $(0.02)$ & 3.1 & 2.10 & - & - & - & - & 1.4 \\
\hline 6 & - & (0) & - & - & 69 & $(0.3)$ & 51 & $(0.8)$ & - \\
\hline 7 & 0.10 & $(0.01)$ & - & 1.20 & - & - & - & (0) & 0.9 \\
\hline 8 & 0.12 & $(0.02)$ & - & - & - & $(0.7)$ & - & $(0.04)$ & 8.5 \\
\hline 9 & 0.43 & $(0.04)$ & - & 7.90 & - & - & - & $(0.1)$ & 2.2 \\
\hline 10 & 0.95 & - & - & 3.00 & - & - & - & $(0.1)$ & $(0.5)$ \\
\hline
\end{tabular}

Values in the front: (ppm in medium) ${ }^{*} 100 /($ At $\%$ in alloy); $n=5 ;($ ) indicates that the ratio was not statistically different from zero. Note that values are unitless.

$\cdots=$ Not checked. 


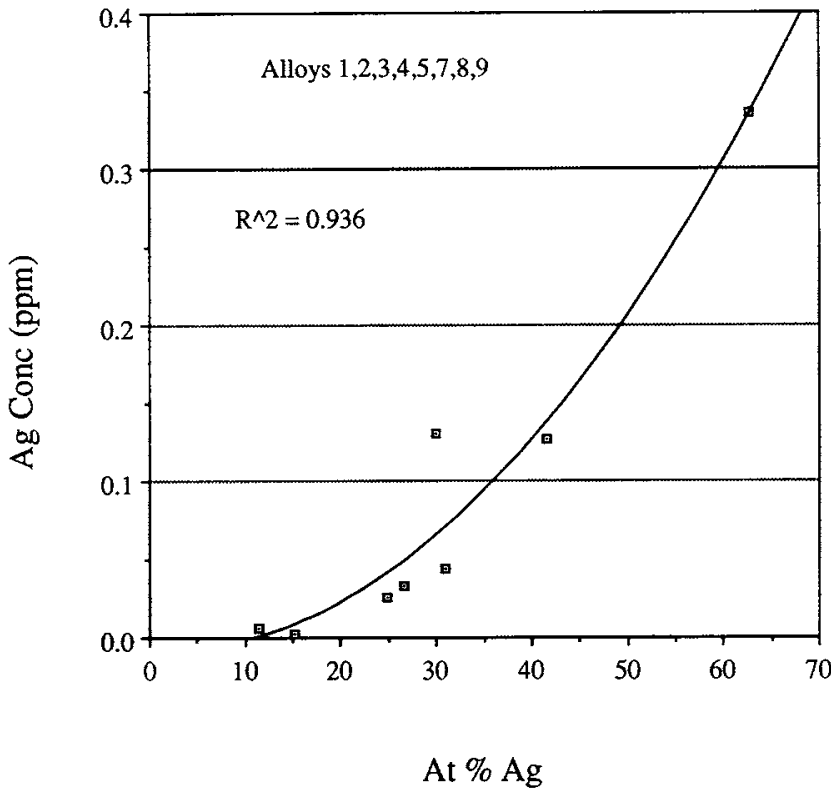

Fig. 3 - Correlation between at\% abundance of $\mathrm{Ag}$ and $\mathrm{Ag}$ release for alloys 1-5 and 7-9. The solid line represents a best fit with use of a secondorder polynomial.

dance of the element in the alloy was small relative to the magnitude of the concentration. These problems were alleviated when $95 \%$ confidence intervals were calculated for the EMA ratios by use of the precision data gathered during each experiment. EMA ratios were considered to be significantly different from zero when their confidence intervals did not include zero. By this definition, EMA ratio data appeared to be more reasonable.

Previous investigations have centered primarily on binary or ternary systems. Wright $e$ t al. (1982) showed that Cu release from simple $\mathrm{Au}-\mathrm{Ag}-\mathrm{Cu}$ alloys was proportional to $\mathrm{Cu}$ content. $\mathrm{Ag}$ and $\mathrm{Au}$ were not detected in their study. In the present study, where more complex commercial systems were used, no such correlation between $\mathrm{Cu}$ content and $\mathrm{Cu}$ release was observed; Ag release was observed and exhibited complex release behavior. These differences in results underscore the importance of using commercial alloy systems if clinical relevance is desired. Simpler systems may be more controllable and understandable, but also may not behave in a clinically relevant fashion. Bumgardner et al. (1989) used commercial Cu-based alloys in their study and detected $\mathrm{Cu}$ and $\mathrm{Zn}$ release, but did not attempt to analyze for other elements in the alloys ( $\mathrm{Al}, \mathrm{Fe}$, $\mathrm{Mn}, \mathrm{Ni}, \mathrm{Co}$, and $\mathrm{Au}$ ). The present study shows that even minor components can be released, and that one cannot simply assume that such release is minor based upon the abundance of the element, because of the complex release behavior of more complex alloy systems. The selective release of elements observed in this study has been recently reported by other investigators. Goehlich and Marek (1990) showed that $\mathrm{Cu}$ or $\mathrm{Co}$ were released from $\mathrm{Pd}-\mathrm{Cu}$ or $\mathrm{Pd}-\mathrm{Co}$ alloys, but that $\mathrm{Pd}$ remained in the alloy and passivated the surface. A similar selective release of $\mathrm{Ag}, \mathrm{Cu}$, and $\mathrm{Zn}$ over $\mathrm{Au}$ and $\mathrm{Pd}$ was observed in the present study.

It was of particular interest to relate alloy element release to alloy toxicity as measured previously (Craig and Hanks, 1990), since release of alloy elements was putatively respon-
TABLE 5

SUMMARY OF ALLOY TOXICITIES PREVIOUSLY REPORTED

\begin{tabular}{cccc}
\hline \hline $\begin{array}{c}\text { Alloy } \\
\text { (Present Study) }\end{array}$ & $\begin{array}{c}\text { Equiv. Alloy } \\
\text { (Craig and Hanks, }\end{array}$ & $\begin{array}{c}\text { Visual } \\
\text { Rank }^{*}\end{array}$ & $\begin{array}{c}\text { Optical } \\
\text { Density } \\
\text { Rank }^{*}\end{array}$ \\
\hline 1 & $1990)$ & 3 & 3 \\
2 & 10 & 3 & 3 \\
3 & 15 & 2 & 3 \\
4 & 26 & 3 & 3 \\
5 & 23 & 4 & 4 \\
6 & 12 & 5 & 5 \\
7 & 8 & 4 & 4 \\
8 & 13 & 2 & 2 \\
9 & 9 & 4 & 4 \\
10 & 14 & 4 & 4 \\
\hline
\end{tabular}

* Rank 1 = least toxic, rank $5=$ most toxic.

sible for these toxic effects. The results of this alloy toxicity work are summarized for convenience in Table 5. In general, alloys that released more of their elements exhibited greater toxicity. Alloys $5,6,7,9$, and 10 showed significant release of their elements (Table 3 ) and were ranked as 4 or 5 . Alloys $1,2,3,4$, and 8 showed less overall release and exhibited toxicity ranks of 2 or 3 . Clearly, the phenomenon of toxicity was dependent upon other factors, such as the potency of each of the alloy elements, their time of exposure, their concentrations, and probably the synergistic or antagonistic effects of combinations of elements. However, this study would support the idea that it was the alloy metal release that was responsible for these toxicities.

\section{Acknowledgments.}

The authors would like to express appreciation to Pat Landry, Susan Stawn, and Dr. Richard Corpron for their assistance and cooperation during these investigations.

\section{REFERENCES}

BERGMAN, M. and GINSTRUP, O. (1975): Dissolution Rate of Cadmium from Dental Gold Solder Alloys, Acta Odontol Scand 33:199-210.

BRUNE, D. (1988): Mechanism and Kinetics of Metal Release from Dental Alloys, Int Endo J 21:135-142.

BUMGARDNER, J.D.; LUCAS, L.C.; and TILDEN, A.B. (1989): Toxicity of Cu-based Dental Alloys in Cell Culture, $J$ Biomed Mater Res 23:1103-1114.

COVINGTON, J.S.; McBRIDE, M.A.; SLAGLE, W.F.; and DISNEY, A.L. (1985): Quantization of Nickel and Beryllium Leakage from Base Metal Casting Alloys, $J$ Prosthet Dent 54:127-136.

CRAIG, R.G. and HANKS, C.T. (1990): Cytotoxicity of Experimental Casting Alloys Evaluated by Cell Culture Tests, $J$ Dent Res 69:1539-1542.

GOEHLICH, V. and MAREK, M. (1990): Corrosion Behavior of Pd$\mathrm{Cu}$ and Pd-Co Alloys in Synthetic Saliva, Dent Mater 6:103-110.

JOHANSSON, B.I.; LEMONS, J.E.; and HAO, S.Q. (1989): Corrosion of Dental Copper, Nickel, and Gold Alloys in Artificial Saliva and Saline Solutions, Dent Mater 5:324-328.

WATAHA, J.C.; CRAIG, R.G.; and HANKS, C.T. (1989): Analysis of Culture Medium for Elements Dissolved from Casting Alloys, $J$ Dent Res 68:322, Abst. No. 1121.

WRIGHT, D.C.; GALLANT, R.F.; and SPANGBERG, L. (1982): Correlation of Corrosion Behavior and Cytotoxicity in $\mathrm{Au}-\mathrm{Cu}-\mathrm{Ag}$ Ternary Alloys, J Biomed Mater Res 16:509-517. 